\title{
Analysis of network technology application in the project construction management process
}

\author{
Zhi.Neng. TONG \\ Jiangxi Science \& Technology Normal University China
}

\section{KEYWORD: Project management;Network planning;Construction process}

ABSTRACT: Method of network plan in project construction has been widely used, it complies with the requirements of the engineering construction management, organization and management is especially suitable for the construction of the project. At present our country network plan technology in engineering project theory and level with the foreign equivalent, but in the application of project management, especially the lag compared the supervision and control in implementing plan, tracking and adjustment, basically still stay on the preparation of the plan. This paper analyzes the present situation of the application of network technology in construction management, puts forward the ways and methods to improve the application of network planning technology.

\section{PREFACE}

Network planning method is used for a management technology planning and control of the project, is a kind of help people analyze work activity law, scientific method prompts the inherent contradiction of the task, this method also provides a set of complete technology planning and adjustment. Network planning the biggest characteristic is that it can provide a variety of information construction management needs, is conducive to strengthening the project management. It helps managers and rational organization of production, do several things, know management should focus on where, how to shorten the construction period, tap potential in where, how to reduce the cost. Improve the application of network planning technique level in project management, will further enhance the level of project management.

The core network planning method that provides a description of the interaction between the schedule (process or organization) logical relations of graphical models -- network diagram. Using this graphical model and relevant calculation method, global can see the planning task, analyzes its rule, in order to reveal the contradiction, to seize the key, and to use scientific methods to adjust the plan arrangement, find out the best scheme. At present, the industrial developed country in the world attaches great importance to the modern science of management, network planning technique has been recognized as the most effective management method. Abroad for many years practice proves that the application of network planning technology, organization and management of production in general can shorten the construction period, reduce cost.

\section{THE NECESSITY OF THE APPLICATION OF NETWORK PLANNING TECHNIQUE}

Construction project construction and general industrial production compared with its own characteristics, performance in the:

The production of space changing

Because the project product is fixed, and the whole construction difficult, so often in the flow process. Change of production space means that the construction conditions or changes in the environment, organization and management of engineering construction project will change with the construction method and order, in order to adapt to the new conditions.

The construction period is longer

The change of construction project with a typically experience four seasons climate conditions, which brings great influence to open construction operation. In order to shorten the construction period, the project can use the large size and other characteristics, organizational multi-level interchange operations and parallel flow operation, the use of space for shortening construction 
period. This method of construction requires close cooperation between different construction units or different types of work, thus the need to develop construction organization plan in detail, and strictly according to plan.

The project of personalized

The project because of its different uses and different geographical location will bring science and technology economic environment changes. Therefore, the project has different characteristics in different construction organization, may not carry out mass production.

The complexity of the project

With the progress of science and technology, the scale and complexity of the project increases continuously. Because of the complexity of the project, it is necessary to execute specialization, so we must strengthen coordination between the various types of work in project construction. The project manager only use project plan, to convey him emphasized schedule, cost, quality engineering and technical personnel.

Has the project construction unit production, the changeable environment and strict and close coordination characteristics, determine the complexity of construction organization and management. Only the application of network planning technology in construction management, a project as a whole to consider, in accordance with certain procedures for its reasonable arrangement, and the plan itself unique feedback effects through the network, adjustment and improvement of construction management, can the construction has been comprehensively to achieve high-quality, saving and fast requirement. The construction practice proves that, the application of network planning technology in construction organization and management of the general can shorten the construction period and reduce the cost.

\section{THE EXISTING PROBLEMS AND REASONS}

Network planning method is not only a method of preparation of the plan, and construction management is a scientific method, but its application in construction management in China is not optimistic.

The existing problems

The application of the penetration rate is not high

Quality differ in thousands of ways of existing construction enterprise in our country, development is very uneven. Directly under the central government and the provincial construction enterprises, the management level is higher, the application of network planning and organization and management of the construction area ratio is higher; at municipal and county level and below the construction enterprises, technology and management level is poor, the application of network planning and organization and management of the construction area ratio is low.

Application of low management level

Application of most of the construction enterprise network plan technology only stay in the planning, the lack of effective management method for planning supervision and control and in the implementation of the plan adjustment.

Application of deep enough

Preparation of construction network plan can often reflect the mutual restriction between each unit of work throughout the project and interdependent relationship, not to determine the relationship between the work unit of work according to the construction method, the preparation of depth is not enough, not to mention the optimization of network plan.

Cause analysis

The cause of network planning technology in construction management in our country application is not ideal in many aspects, both the influence of the external environment, but also restrict the construction enterprise's quality is not high, is the result of comprehensive effect of multiple factors.

The influence of the external environment

The influence of the external environment including engineering design variable, determined by the duration of the administrative interference, the progress payment, no contact closely with network planning project payment default etc. 
Engineering design change often very difficult to bring the formulation and adjustment of network plan, the construction enterprises too busy to attend to all, unable to use the network to implement the construction management plan; identify some project construction period to violate scientific rule, the project completion date in advance and again also enable enterprises to go to the organization management according to the network planning; project payment is not timely and payment without and network plan closely, but also objectively weakened the enterprise application of network planning responsibility.

Control the quality of their own

(1) The traditional ways of working to hinder. Traditional construction management uses the manual management and a lot of work is to rely on experience to complete, lack of the necessity to carry out the network plan management of enterprise knowledge. Personnel of a lot of construction network plan is rejected because it is not customary network plan management, the traditional management mode is not so handy.

(2) Extensive construction management. In the management of construction site tracking examination did not form a system, optional sex is big, the progress of data collection is not comprehensive, not complete, schedule the collation of data, statistics, analysis, processing ability is poor, no person responsible for such.

(3) High quality management personnel lack. At present, most of the construction enterprise management personnel and engineering and technical personnel, they often focus only on the study of construction technology, schedule management depends on the Gantt chart management, to master the knowledge of network planning technique and lack of systematic and comprehensive.

\section{THE METHODS OF IMPROVING THE APPLICATION LEVEL}

According to the above analysis, the construction enterprises to improve the application level of network plan technology, apart from the source, the development of effective measures to enhance the enthusiasm of the enterprise application of network plan technology, more important is to improve the market competitiveness of the enterprise itself from the height, through the full implementation of network planning to promote enterprise management quality, on level.

Specification of construction management system, provides a good environment for the application of network technology

(1) Strengthen the management of engineering design, determine the reasonable construction period. Through the establishment of regulations and systems, to promote the engineering design and construction period to determine the scientific and rational design, the subjective determination of the prohibition of frequent changes and construction period.

(2) Improve project supervision system. At the same time engineering supervision in engineering quality supervision, to project schedule supervision, to ensure consistency and coordination of the progress control and investment control, quality control.

(3) Set up the mechanism of allocation of Engineering in strict accordance with the network progress plan. In combination with engineering disbursed and network schedule, not only improve the enterprise application of network plan consciousness of construction management, but also make the network planning more feasible.

To adapt to the need of scientific management, strengthen personnel training and applied research

(1) To formulate relevant regulations, strengthen standardization work. According to the situation of China and the characteristics of the industry, develop the network plan technology preparation and management procedures, network model, unified descriptive terms and of various types, and is convenient for popularization and application.

(2) The cultivation of talents in multiple ways. Industry associations and administrative departments should organize the preparation of practical training materials, hosting the network planning technology and computer application training, training of construction enterprise technology leadership and construction management personnel, to learn and master the technology of network plan; colleges and universities should increase technology course of modern management, the students after graduation can adapt to the needs of modernization of management the. 
Raise awareness, pay attention to actual effect, do solid work to improve the management level of enterprise

Construction enterprise is the main body of the application of network planning technology in construction, the full implementation of network planning management is the key to improve the management level of construction enterprise in our country.

(1) Change idea, fully understand the importance of application of network planning techniques. The biggest characteristic of network planning method is that it can provide a variety of information construction management needs, help managers and rational organization of production. Will the construction management in the promotion and application of network planning method to get the full effect is good fast Province, further improve the construction management level.

(2) The use of easy to control the form of acceptance. The bar chart is the most familiar form of control engineering and technical personnel, is intuitive, easy to understand, easy drawing characteristics, required less time, low cost, but its drawback is that can't reflect the relationship between various work of interdependence, mutual restriction, the difficulties of large and mediumsized project schedule control. In the network planning technology and adjusting production schedule, converted into a bar chart form to implement, which has tight network like, and has the advantages of simple Gantt chart, network plan to reduce the resistance in the.

(3) Closely combining the management personnel and technical personnel. The preparation and implementation of network planning is established on the basis of known construction method, construction management personnel in addition to the familiar network planning method, but also understanding of technology and organization of the work of the. According to the nature and characteristics of network planning method, not the application of network planning technique will shorten the project period, it only to provide the management staff should be reasonable acceleration and the relationship between duration and cost in which work and other information. Therefore, management personnel formulate scientific and rational schedule control plan must be closely combined with the engineering and technical personnel.

(4) Regularly check the network planning is the most effective method to supervise the implementation of the plan. The necessary correction, is to ensure the smooth realization of the project network schedule measures. During the execution of certain requirements, a relatively stable plans, this is the basis of network planning management. Regular and timely records, check the schedule plan execution, not only can adjust the network basis, but also help to accumulate data, engineering analysis and summary, and constantly improve the level of planning and network planning management level.

The network planning technology is a scientific construction management ideals and methods, its application is not only a technical problem, but also relates to the factors of project management system and associated with the project units, individuals and other aspects of the. Application of network plan technology, enterprise leadership attention is the key, to provide a good environment and strengthening external guidance is an effective way to improve the application level of enterprise.

\section{REFERENCE}

1.Yuan Ziren etc Construction management network [M] Chinese Building Industry Press 1987 2.Liu Shixian Construction project schedule control $[\mathrm{M}]$ Water conservancy and electric power press 1994

3.Chinese network plan technology Daquan [M] Seismological Press 1994 